\title{
The Influence of Polymer Structure on the Physical Characteristic of Intraoral Film Containing BSA-loaded Nanoemulsion
}

Heni Rachmawati ${ }^{1,2 *}$ and Bernard Manuel Haryadi ${ }^{1}$

${ }^{1}$ School of Pharmacy, Bandung Institute of Technology, Ganesha 10, Bandung 40132, Indonesia

${ }^{2}$ Central for Advanced Sciences, Bandung Institute of Technology, Bandung 40132, Indonesia

\begin{abstract}
Therapeutic protein has limitation, both in stability and invasive route of administration. Therefore, formulation to optimize the use of therapeutic protein becomes the research focus of interest. The purpose of this study was to develop nanoemulsion as a carrier system for a standard-model protein drug - bovine serum albumin (BSA). BSA-loaded nanoemulsion was then formulated into hydrophilic film for intraoral route. The influence of polymers was evaluated in relation to physical property of the film. Nanoemulsion was prepared using self assembly method with composition of Glyceryl monooleate (GMO), Cremophor RH-40 and Polyethylene glycol (PEG 400), with ratio of 1:8:1. The film was prepared using different polymers and plasticizers with solvent casting technique. Standard characterization of BSA nanoemulsion was including droplets size, size distribution, zeta potential, morphology, and entrapment efficiency. Physical properties of the film containing BSA nanoemulsion was included macroscopic of film, film thickness, film weight uniformity, folding endurance, tear resistance, Tensile strength (TS), percentage of elongation (PE), Elasticity modulus (EM) and film morphology. Based on all evaluated parameters, Carboxy methyl chitosan (CMCs) produced better film suitable for intraoral dosge form. Critical factors such as type and ratio of film-forming polymer, plasticizer, process and BSA concentration influenced the film characteristics.
\end{abstract}

Keywords: Therapeutic protein; Bovine serum albumin; Self assembly nanoemulsion; Intraoral; Film; Water soluble chitosan

\section{Introduction}

Protein which is major part of pharmaceutical biotechnology product is predicted to be used increasingly as a therapeutic agent in the future. In fact, it has been estimated that biotechnology products in the next 20 years will take half of the world drug market [1]. According to the top 200 products sales in United States in 2010, eight protein-based biotechnology products were in top 30, in which these eight products were also classified top 10 biopharmaceutical product in Europe [2,3].

However, administration route of therapeutic proteins in particular for systemic treatment is still restricted to invasive route due to the low bioavailability of protein when given by non-invasive way. This low bioavailability mainly due to enzymatic degradation, poor absorption and first-pass effect metabolism. Many significant efforts have been developed to obtain the best non-invasive route for delivering protein to overcome disadvantages of invasive route, such as pain during administration, poor patient acceptance, and necessity to get particular degree of sterility. Among non-invasive routes, intraoral route (buccal and sublingual) is considered as the most promising way to deliver protein for systemic purposes. In addition, some advantages like ease of access, availability of tough mucosa tissue, avoidance of intensive first past effect and degrading enzymes, potential to improve bioavailability with rapid onset, and promising patients acceptance, convenience and adherence because the drug can be administered by themselves without help from paramedics.

Among other intraoral preparations, film dosage form is recently considered to deliver active substances with small doses. The film has a relatively larger surface area than other solid dosage forms, so it is easier to be moistened hence resulting rapid disintegration and dissolution, more flexible, not fragile and brittle when transporting or handling. Moreover, with the use of mucoadhesive material, it will increase the contact time therefore extending the absorption time [4].

In this study, BSA was used as a standard-model protein drug aimed for intraoral use. To improve its stability and absorption, BSA was encapsulated in oil in the oil-in-water nanoemulsion system. This carrier was developed by Self-Nanoemulsifying (SNE) technique. Using this method, nano-carrier was spontaneously produced with nanometer-scaled droplets when the system was dispersed in aqueous phase with mild stirring of $60 \mathrm{rpm}$. Then, two different polymers (Carboxy methyl Chitosan and Methocel E15) were selected to obtain best film matrix which was able to accommodate BSA nanoemulsion. Both physical and chemical evaluations of nanoemulsion as well as the film were performed including droplets size, droplets size distribution and zeta potential, the content of BSA in the oil droplet, mechanical properties of film (tear resistance, TS, PE and EM), homogeneity and distribution of nanoemulsion droplets in film, as well as other parameters that related to film dosage form.

\section{Material and Methods}

\section{Materials}

Methocel ${ }^{\circledR}$ E15 was from Colorcon Indonesia, Carboxy methyl Chitosan (CMCs) was purchased from Eastar Holding Group (China), Bovine Serum Albumin (BSA) was from Sigma Aldrich (Singapore), Soy phosphatidyl choline (SoyPC; Lipoid ${ }^{\circledR}$ S100) was from PT. Dankos Farma Indonesia, Glyceryl Monooleate (GMO) from PT. Tritunggal Artha Makmur (Indonesia), Cremophor RH-40 from BASF (Germany), PEG 400, Phosphate Buffer Saline (PBS), Trichloroacetic (TCA) were from Merck (Germany), Glycerin, Propylene Glycol (PG) were from

*Corresponding author: Heni Rachmawati, School of Pharmacy, Bandung Institute of Technology, Ganesha 10, Bandung 40132, Indonesia, Tel/Fax: +6222-2504852; E-mail: h_rachmawati@fa.itb.ac.id or hrachma@yahoo.com

Received January 23, 2014; Accepted February 19, 2014; Published February 21, 2014

Citation: Rachmawati H, Haryadi BM (2014) The Influence of Polymer Structure on the Physical Characteristic of Intraoral Film Containing BSA-loaded Nanoemulsion. J Nanomed Nanotechnol 5: 187. doi:10.4172/2157-7439.1000187

Copyright: ( 2014 Rachmawati $\mathrm{H}$, et al. This is an open-access article distributed under the terms of the Creative Commons Attribution License, which permits unrestricted use, distribution, and reproduction in any medium, provided the original author and source are credited. 
PT. Brataco (Indonesia), Bradford Reagent was purchased from Biorad (USA). All other reagents were analytical grade and were used without further purification.

\section{Preparation of BSA-loaded nanoemulsion}

Prior to BSA incorporation, the protein was dispersed in Soy PC to improve oil solubility. Solid dispersion complex of BSA-soy PC was prepared by mixing BSA with Soy PC in the ratio of 1:3 in PBS and then freeze-dried (Christ ${ }^{\circledR}$ Alpha 2-4 LSC). Internal phase (IP) of BSA nanoemulsion was consisted of GMO as an oil, Cremophor RH-40 as surfactant and PEG 400 as co-surfactant (1:8:1). Various amount of BSA was added into internal phase $(1,3,4,5,6,9$ and 12 $\mathrm{mg} / 1 \mathrm{~g}$ oil phase). This mixture was stirred for $2 \mathrm{~h}$ at $100 \mathrm{rpm}$ and then sonicated (Branson ${ }^{\circledR}$ model 5510 ) for $1 \mathrm{~h}$. Subsequently, the IP was mixed with deionized water (in the ratio of 1:4) to form spontaneous BSA nanoemulsion. Several parameters were measured such as $\mathrm{pH}$ using Mettler Toledo ${ }^{\circledR}$ S20, droplets size and droplets size distribution using Photon Correlation Spectroscopy (PCS) and zeta potential was determined by Electrophoretic Light Scattering (ELS).

\section{Transmission electron micrograph of BSA-loaded nanoemulsion}

The morphology of nanoemulsion was observed using a transmission electron microscope (TEM; JEM 1400, JEOL, Japan). About $10 \mu \mathrm{L}$ of sample was dropped in specimen place and covered with 400 mesh grid. After 1 minute, $10 \mu \mathrm{L}$ of uranyl acetate was dropped above the grid, and allowed to dry for 30 minutes before observation under the electron microscope. This data was also aimed to confirm the particle size of the nanoemulsion measured using particle size analyzer.

\section{Determination of entrapment efficiency}

Entrapment efficiency was determined using indirect method. One part of nanoemulsion was added into 4 parts of $2 \%$ Trichloro acetate (TCA) solution, then the mixture was centrifuged at 12,000 rpm for 5 min. The precipitated BSA was washed triplicate with $2 \%$ TCA solution, each $100 \mu \mathrm{L}$. Further, it was dissolved in $1 \mathrm{~mL}$ deionized water. $40 \mu \mathrm{L}$ protein solution was reacted with $2 \mathrm{~mL}$ Bradford reagent. The mixture was incubated for $5 \mathrm{~min}$ and the absorbance was measured using visible spectrophotometer (Beckman ${ }^{\circledR} \mathrm{DU} 650 \mathrm{i}$ ) at $\lambda_{\text {max }} 595 \mathrm{~nm}$. As a calibration curve, BSA solution was used (within range of 0-500 ppm). Percentage of entrapment efficiency was calculated using equation:

Entrapment efficiency $(\%)=\frac{\text { added protein into SNE }- \text { free protein }}{\text { added protein into SNE }} \times 100 \%$

\section{Development of film matrix containing BSA-loaded nanoemulsion}

Film-forming polymers were prepared by dissolving each polymer (Methocel E15 and CMCs) using deionized water and plasticizer (glycerin and propylene glycol). The polymer solution was poured into flat and clean container (petri dish) then dried at room temperature for 48 hours. This technique is known as solvent casting. Both Methocel E15 and CMCs films were evaluated including macroscopic appearance, film thickness, film weight, film morphology, folding endurance, disintegration time, dissolution time, tear resistance, tensile strength (TS), percent elongation (PE) and elasticity modulus (EM).

\section{Film characterization}

Film thickness: Film thickness was measured using digital micrometer screw (Mitutoyo ${ }^{\circledR}$ CD-6" CS) on three different locations of film.

Film weight variance: Film weight was measured using analytical balance (Mettler Toledo XS204).

Folding endurance: The folding endurance of the films was determined by repeatedly folding one film at the same place till it broke or folded up to 300 times, which is considered satisfactory to reveal good film properties. The film was folded number of times at the same place without breaking gave the value of the folding endurance [5].

Disintegration and dissolution time: Disintegration and dissolution time was determined using visual observation in $25 \mathrm{~mL}$ distilled water $\left(37^{\circ} \mathrm{C}\right)$ on petri dish with swirling movement every 10 seconds. Disintegration time is the time when films were broken or disintegrated, meanwhile dissolution time is the time when film is totally dissolved [6].

Determination of mechanical properties: Tear Resistance, TS, PE and EM: Film sample was cut using sharp cutter die. Film (with a stress-exposed area of $25 \mathrm{~mm} \mathrm{x} 4 \mathrm{~mm}$ ) was put between two jaws of the machine (Shimadzu ${ }^{\circledR}$ AGS 500D or Tensilon ${ }^{\circledR}$ UCT-5T to get stressstrain curves). Upper jaw was movable while the lower jaw was static. Stress was applied perpendicularly to film gradually (at speed of $5 \mathrm{~mm} /$ $\mathrm{min}$ ) and automatically until the film was broken. The maximum stress required to the specimen was called as tear resistance (in N).

Film morphology: Morphology of film was observed using Scanning Electron Microscope. Film sample was cut fit with specimen container. Specimen container was spread by silver pasta in several points just before sample was laid and above the film then let it dried at $20^{\circ} \mathrm{C}$. Sample was put in fine coat instrument (Jeol ${ }^{\circledR}$ Ion Sputter JFC1100) that had been set up using $1,2 \mathrm{KV}$ voltage, 6-7,5 $\mathrm{mA}$ current and 0.2 Torr air pressure for 4 minutes hence sample thickness about 400 A. Ready-to-test sample was then put in SEM instrument (Jeol ${ }^{\circledR}$ JSM6360LA).

\section{Data analysis}

Statistical data analysis was performed using two tailed student t-test with $95 \%$ confidence interval. P-Value $<0.05$ was considered as the minimal level of significance. The t-test was performed to compare various BSA loading amount in SNE for droplets size, droplets size distribution, zeta potential, entrapment efficiency and nanoemulsion $\mathrm{pH}$ and also to compare Methocel E15 and CMCs for mechanical properties.

\section{Results and Discussion}

\section{Preparation of BSA-loaded nanoemulsion}

The appropriate type and ratio of oil phase, surfactant and cosurfactant are critical points in self nanoemulsification process. Based on our previous work, the best ratio between GMO as oil, Cremophor RH-40 as surfactant and PEG 400 as co-surfactant to form nanoemulsion was $1: 8: 1$, respectively.

Sufficient length of carbon chain and high HLB value of fatty acids as oil was required to form good self nanoemulsion. Combination of GMO, unsaturated fatty acid, has 21 carbon chains, and Cremophor RH-40, surfactant with HLB value of 14-16 [7], forms nanoemulsion with self assembly.

Figure 1 shows a simple visual observation of the BSA-loaded nanoemulsion. Faraday-Tyndall effect is optical characteristic of 
Citation: Rachmawati H, Haryadi BM (2014) The Influence of Polymer Structure on the Physical Characteristic of Intraoral Film Containing BSAloaded Nanoemulsion. J Nanomed Nanotechnol 5: 187. doi:10.4172/2157-7439.1000187

Page 3 of 6

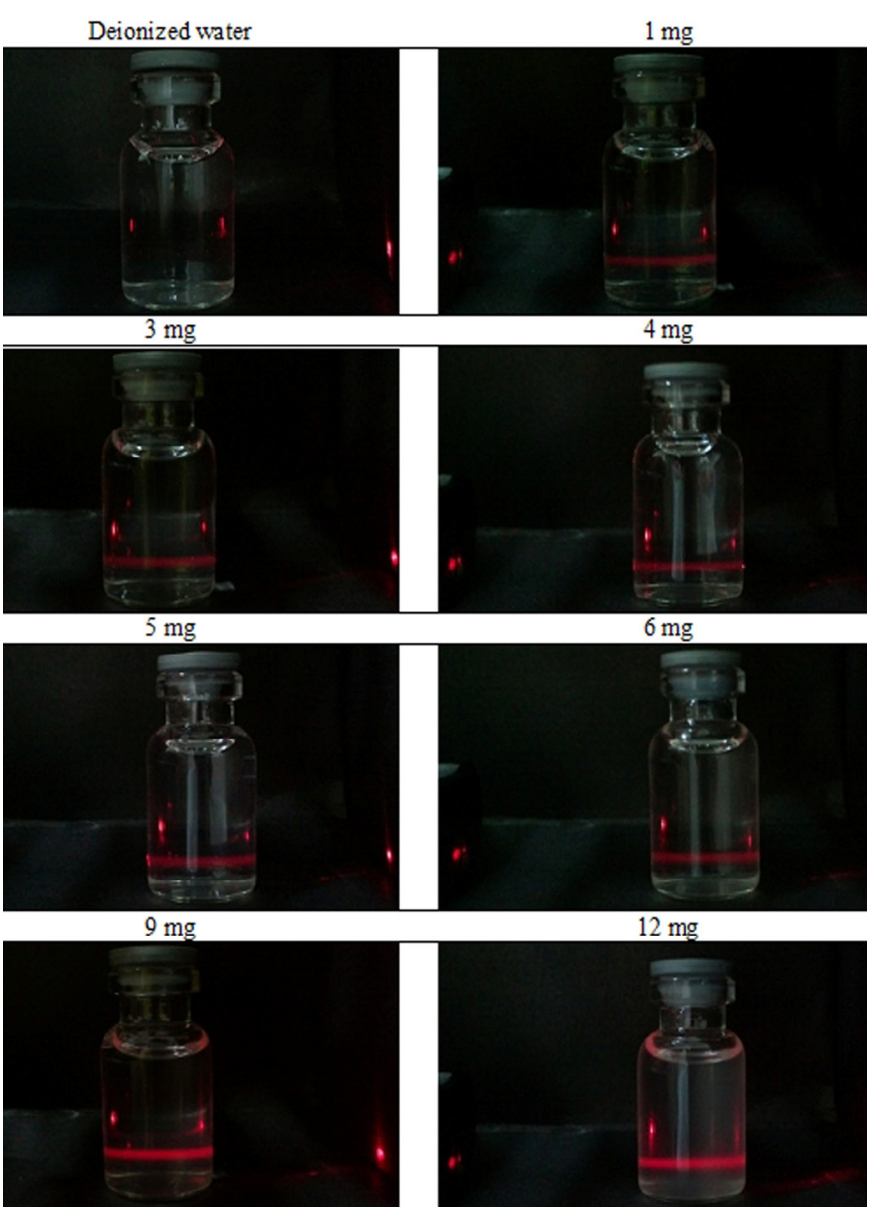

Figure 1: The Faraday-Tyndall effect observation on BSA-loaded nanoemulsion with different BSA concentrations. The red beam width easily indicated the particle size of oil globules.



Figure 2: The influence of BSA added in the formula on the droplet size.

colloidal system, when a very strong light beam is passed through colloidal system, it will be seen as a conical light beam generated by the scattering of light by colloidal particles [8]. Light scattering will be stronger therefore can cause cone beam more noticeable when the size of the dispersed phase increases. So, Faraday-Tyndall effect could be as the one of the simple evaluation to see stability of nanoemulsion based on droplets size [9].

The Faraday-Tyndall effect observation was confirmed by particle size of the nanoemulsion measured with PCS method (Table 1). As seen, also in Figure 2, the amount of BSA in the formula influenced the droplets size. The relationship was not linear because of unpredictability of macromolecular protein spatial orientation in internal phase.

The size distribution of the droplets was indicated by polydispersity (PI) index value. The PI of all formulas using different amount of BSA showed less than 0.5 which was indicated the narrow particle distribution of the nanoemulsion globules. In addition to the size distribution of the globules, surface charge (represented by zeta potential value) of the globules contributes on the physical stability of the nanoemulsion. Zeta potential value of blank nanoemulsion and nanoemulsion with different amount of BSA were less than $-8 \mathrm{mV}$. Zeta potential is the value which is measured by electrostatic double-layer surface of droplets. High zeta potential should be achieved (greater than $\pm 30 \mathrm{mV}$ ) in the emulsion to ensure a high-energy barrier against coalescence [10]. However, the value of zeta potential is suggested based solely on the value generated from experiments and cannot be reliably used to predict SNE stability as reported by other investigators $[11,12]$. The lower zeta potential values in this study were due to non-ionic surfactant used in the formula. Nonionic surfactant stabilizes system by steric hindrance to avoid droplets aggregation during storage. Zeta potential values were significantly different between blank nanoemulsion and BSA-loaded nanoemulsions which showed chemical interaction between BSA, surfactant, co-surfactant and oil. The hydrogen bonds were formed between the hydroxyl groups of active substance with some functional groups containing oxygen or nitrogen atoms in surfactant, co-surfactant and oil that can lead the changes of zeta potential value.

All formulas using different amount of BSA showed high entrapment efficiency of nearly $90 \%$ with maximum loading capacity of $1 \mathrm{mg}$ BSA in $1 \mathrm{~g}$ of oil phase. This formula was then used for further study.

The morphology of BSA nanoemulsion was analyzed using TEM and presented in Figure 3. Visualization of the nanoemulsion preparations using transmission electron microscopy (TEM) imaging is likely the most powerful and accurate technique to determine the specimens' morphology, purity and particle size distribution. As revealed on Figure 3, the droplets were distributed evenly and the particle size was uniform confirming the particle size measured with photon correlation spectrophotometer (PCS).

\section{Preparation of intraoral film containing BSA-loaded nanoemulsion}

Methocel E15 and CMCs were used in this research due to excellent

\begin{tabular}{|c|c|c|c|c|}
\hline $\begin{array}{c}\text { Amount of } \\
\text { added BSA } \\
\text { into 1 g SNE }\end{array}$ & $\begin{array}{c}\text { Droplets Size } \\
\text { (nm) }\end{array}$ & $\begin{array}{c}\text { Polydispersity } \\
\text { Index }\end{array}$ & $\begin{array}{c}\text { Zeta Potential } \\
\text { (mV) }\end{array}$ & $\begin{array}{c}\text { Entrapment } \\
\text { efficiency (\%) }\end{array}$ \\
\cline { 3 - 5 } Blank & $15.33 \pm 0.31$ & $0.136 \pm 0.016$ & $-7.37 \pm 0.31$ & - \\
\hline $1 \mathrm{mg}$ & $17.60 \pm 0.66$ & $0.123 \pm 0.015$ & $-5.72 \pm 0.34$ & $96.84 \pm 0.15$ \\
\hline $3 \mathrm{mg}$ & $16.90 \pm 1.67$ & $0.273 \pm 0.025$ & $-5.11 \pm 0,27$ & $96.40 \pm 0.11$ \\
\hline $4 \mathrm{mg}$ & $18.17 \pm 1.15$ & $0.207 \pm 0.044$ & $-4.26 \pm 0.04$ & $96.23 \pm 0.12$ \\
\hline $5 \mathrm{mg}$ & $61.30 \pm 15.09$ & $0.149 \pm 0.010$ & $-2.80 \pm 0.18$ & $96.24 \pm 0.25$ \\
\hline $6 \mathrm{mg}$ & $110.50 \pm 5.78$ & $0.183 \pm 0.017$ & $-2.33 \pm 0,04$ & $95.85 \pm 0.07$ \\
\hline $9 \mathrm{mg}$ & $289.67 \pm 3.90$ & $0.298 \pm 0.061$ & $-1.25 \pm 0.09$ & $94.60 \pm 0.11$ \\
\hline $12 \mathrm{mg}$ & $1022.57 \pm 49.91$ & $0.380 \pm 0.023$ & $-0.09 \pm 0.02$ & $94.39 \pm 0.16$ \\
\hline
\end{tabular}

Data is shown as mean + standard deviation, $n=3$

Table 1: Correlation between BSA concentration and nanoemulsion characteristics. 


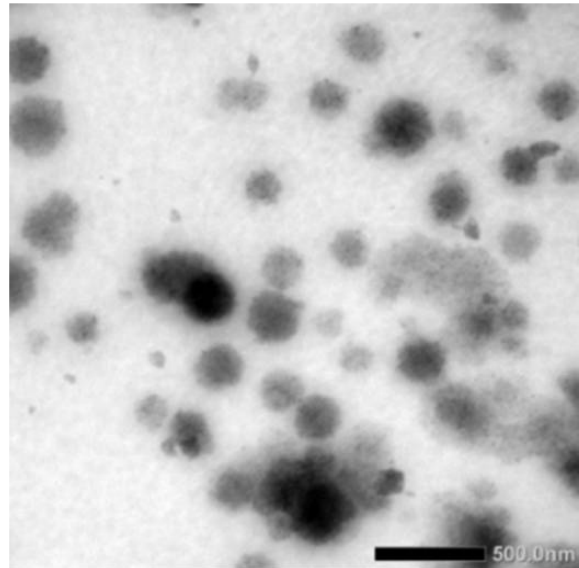

Figure 3: Transmission Electron Microscopic (TEM) image of BSAloaded nanoemulsions (magnification: 10,000X)

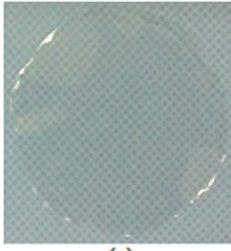

(a)



(c)

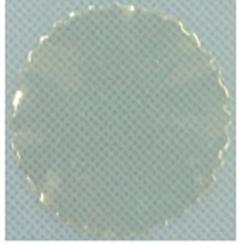

(b)



(d)
Figure 4: Macroscopic appearances of films formed from different type of polymers (a) Methocel E15 blank film, (b) CMCs blank film, (c) Methocel E15 film containing BSA nanoemulsion, and (d) CMCs film containing BSA nanoemulsion.

film-forming capacity and its mucoadhesive property. Film forming capacity was assessed based on speed and ease of film formation (Figure $4 \mathrm{a}$ and $4 \mathrm{~b}$ ). Optimization of drying condition showed that drying at room temperature for 48 hours produced film with more flat-surface. Drying at higher temperature $\left(40^{\circ} \mathrm{C}\right)$ resulted srinking film which is not expected for film dosage form.

According to all parameters studied, the optimum concentration of Methocel E15 and CMCs IFPN was 8\%, with ratio of polymer: BSA-loaded nanoemulsion $=76: 24,10 \%$ PG as plasticizer. Wrong composition resulted in nanoemulsion instability as shown in Figure 5. This phenomenon was occurred as the effect of high surface activity of Methocel E15 as a colloidal hydrophilic polymer. In addition, Methocel E15 is also capable to be adsorbed at the interface of oil/water interface to form films [13], which in this case, leading to competition between Methocel E15 and Cremophor RH-40 in stabilizing the internal phase of nanoemulsion.

Methocel are available in type K, F and E. Surface tension of different types of Methocels (with same viscosities grade) decreases slightly in the following order: K, F and E. In each type of Methocel, molecular weights (or viscosities) practically did not affect the surface and interfacial activity. Methocel $0.3 \%$ can reduce the surface tension of free from trace surface-active impurities water from $72.7 \mathrm{mN} / \mathrm{m}\left(20^{\circ} \mathrm{C}\right)$, to within the range of $47.5-53 \mathrm{mN} / \mathrm{m}\left(20^{\circ} \mathrm{C}\right)$ in the $20^{\text {th }}$ minutes, in accordance with Methocel type. The lower surface or interfacial tension of gum solution, the higher surface or interfacial activity. Type K, F and $\mathrm{E}$ of Methocel are distinguished by the substitution degree of hydroxyl groups in the molecule. Type $\mathrm{K}$ has the highest number of hydroxyl group while type $\mathrm{E}$ has lowest number of hydroxyl group [13]. Thus, the presence of hydroxyl groups in the hydroxypropyl groups contributes to lower surface activity.

As its function, hydrophilic colloid increases viscosity of the medium through double layer formation around the droplets without showing activity on the surface or interface. Other hydrophilic colloids such as methyl cellulose (Methocel A), hydroxypropyl cellulose and carboxy methyl cellulose (CMC) are able to work both in enhancing viscosity and lowering surface tension, due to the presence of hydrophilic and lipophilic groups. Decrease in surface tension is not the only indicator for emulsion stability. The presence of particular functional groups are alsoresponsible in maintaining the stability of the emulsion [13].

Carboxy methyl Chitosan (CMCs) is a water-soluble chitosan derivative and has a weak surface activity because of the absence of a hydrophobic group. Surface tension of O-CMCs in O-CMCs with concentration $>0.05 \mathrm{mg} / \mathrm{mL}$ tends to not rely on the concentration [14]. This explains why the O-CMCs is resulting good film when the BSA-loaded nanoemulsion was added. In addition, chitosan is the strongest mucoadhesive polymer due to the strong positive charge, resulting very good matrix for intraoral film. CMCs can also protect proteins from enzymatic degradation and opens gap between the tight junctions of epithelial cells to facilitate the transport of macromolecules across the membrane.

The film properties prepared with both Methocel and CMCs are presented in Table 2 and Figure 7. In this study, the films prepared using $37 \mathrm{~mm}$ in diameter showed good weight homogenity. All films showed

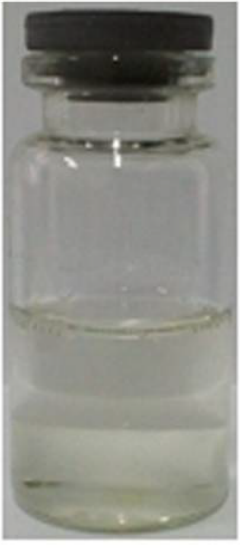

A



B
Figure 5: Visual appearance of the mixture of polymer solution and BSAloaded nanoemulsions. Demulsification process was occurred when nanoemulsion was incorporated into Methocel E15 solution. A. Methocel E15 solution; B. Mixture of nanoemulsion and Methocel E15. 
Citation: Rachmawati H, Haryadi BM (2014) The Influence of Polymer Structure on the Physical Characteristic of Intraoral Film Containing BSAloaded Nanoemulsion. J Nanomed Nanotechnol 5: 187. doi:10.4172/2157-7439.1000187

Page 5 of 6

\begin{tabular}{|c|c|c|c|c|}
\hline Parameter & Methocel E15 Blank Film & $\begin{array}{c}\text { Methocel E15 + BSA } \\
\text { nanoemulsion }\end{array}$ & CMCs Blank Film & $\begin{array}{c}\text { CMCs } 8 \% \\
+ \text { BSA nanoemulsion }\end{array}$ \\
\hline $\mathrm{pH}$ & $7.10 \pm 0.02$ & $6.88 \pm 0.02$ & $8.55 \pm 0.02$ & $7.45 \pm 0.03$ \\
\hline Viscosity $(\mathrm{cps})^{*}$ & $875.00 \pm 0.00$ & $1206.67 \pm 2.89$ & $520.00 \pm 0.00$ & $842.67 \pm 2.89$ \\
\hline Thickness (mm) & $0.052 \pm 0.005$ & $0.093 \pm 0.004$ & $0.049 \pm 0.004$ & $0.099 \pm 0.005$ \\
\hline Weight Variance (mg) & $54.70 \pm 0.20$ & $81.90 \pm 0.40$ & $55.27 \pm 0.25$ & $84.13 \pm 0.12$ \\
\hline Folding Endurance (times) & $>300$ & $>300$ & $>300$ & $>300$ \\
\hline Disintegration Time (seconds) & $59.33 \pm 1.53$ & $83.67 \pm 1.53$ & $14.67 \pm 3.06$ & $32.67 \pm 1.53$ \\
\hline Dissolution Time (seconds) & $155.00 \pm 2.65$ & $184.67 \pm 2.52$ & $92.00 \pm 1.00$ & $124.67 \pm 2.52$ \\
\hline Tear Resistance $(\mathrm{N})$ & $16.10 \pm 1.17$ & $4.47 \pm 0.51$ & $10.55 \pm 1.69$ & $6.71 \pm 0.42$ \\
\hline Tensile Strength (MPa) & $57.23 \pm 4.18$ & $12.23 \pm 1.40$ & $38.64 \pm 5.72$ & $18.35 \pm 0.60$ \\
\hline$\%$ Elongation & $20.85 \pm 3.24$ & $21.75 \pm 5.24$ & $32.87 \pm 3.22$ & $34.23 \pm 2.00$ \\
\hline Elasticity Modulus (MPa) & $1284.00 \pm 86.55$ & $285.82 \pm 23.95$ & $674.84 \pm 67.65$ & $241.77 \pm 55.42$ \\
\hline
\end{tabular}

Data is shown as mean + standard deviation, $\mathrm{n}=3$

* using Brookfield DV-I Viscometer (S28 spindle and $100 \mathrm{rpm}$ in room temperature)

Table 2: Influence of film-forming polymers on the film characteristics.

\begin{tabular}{|c|c|c|c|}
\hline \multirow{2}{*}{ Film Characteristics } & \multicolumn{2}{|c|}{ Properties } \\
\cline { 2 - 3 } & Tensile Strength & Elongation \\
\hline Soft \& weak & Low & Low & Low \\
\hline Strong \& brittle & Moderate & High & High \\
\hline Soft \& tough & Moderate & High \\
\hline Hard \& tough & High & Low \\
\hline
\end{tabular}

Table 3: Classification of film based on mechanical properties.

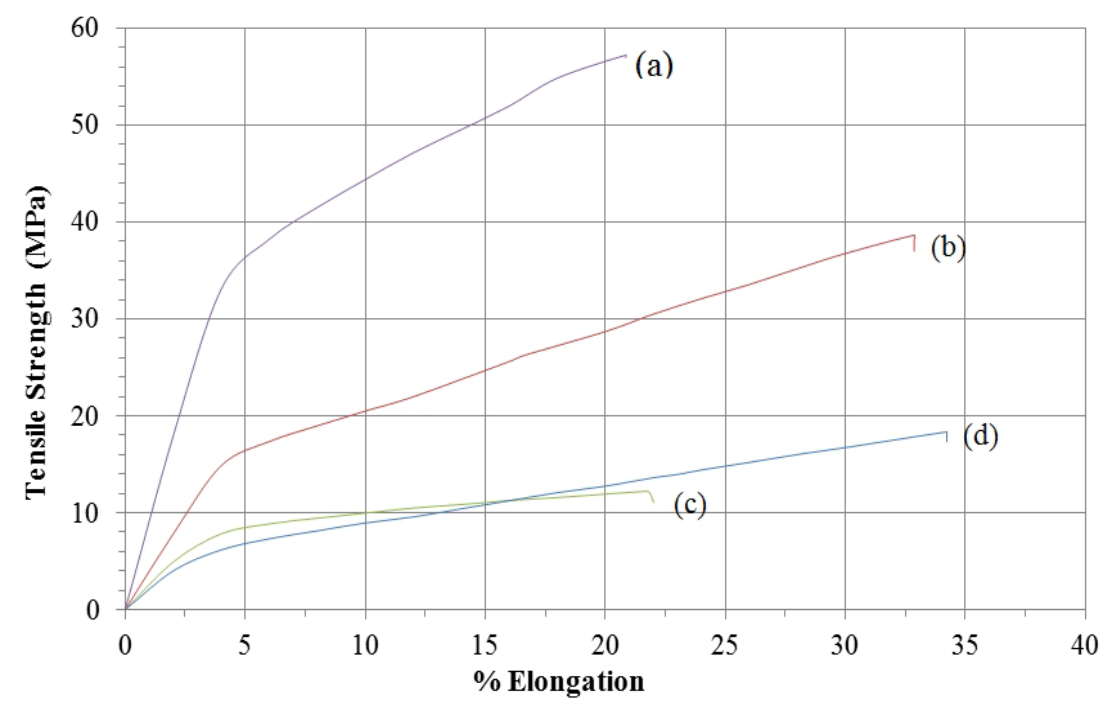

Figure 6: Stress-strain curve of (a) Methocel E15 blank film, (b) CMCs blank film, (c) Methocel E15 containing BSA nanoemulsion , and (d) CMCs containing BSA nanoemulsion (each curve is mean of triplicate measurements).

folding endurance more than 300 times, which indicate good flexibility properties [15]. Intraoral films should be flexible, soft, but strong enough to resist from the mouth activities [16]. Generally, the film is classified based on the mechanical properties as shown in Table 3 [17]. Ideal intraoral films should have mechanical properties: high tensile strength and percent elongation and low elasticity modulus [18]. BSA nanoemulsion-incorporated Methocel E15 and CMCs films showed TS values within the range of tens $\mathrm{MPa}$ (Table 2 and Figure 6), which is classified as soft film [19]. The stress-strain curve shown in Figure 6 explained the physical characteristic of film to be plastic and ductile. Where, all curves started with elastic deformation, subsequently were followed by a yield point and plastic deformation. Ductility is the state where plastic deformation is still maintained during the breaking phase.
Ductility is important in related to manufacturing process [20]. The EM values representing stiffness was shown by slope of elastic deformation region: the steeper the slope, the stiffer the material [8].

Toughness of a material can be seen from the energy required to break the film, which is indicated by area under the stress-strain curve. The larger area under the curve, the more powerful the polymer to form the film $[8,20]$. Incorporation of BSA-loaded nanoemulsion increased the toughness of both Methocel and CMC films. It was suggested that nanoemulsion contributed on partial plasticization, indicated by the decreased in TS and EM values. Both TS and EM values of BSA-loaded nanoemulsion Methocel E15 and CMCs films are not statistically different. 
Citation: Rachmawati H, Haryadi BM (2014) The Influence of Polymer Structure on the Physical Characteristic of Intraoral Film Containing BSAloaded Nanoemulsion. J Nanomed Nanotechnol 5: 187. doi:10.4172/2157-7439.1000187

Page 6 of 6
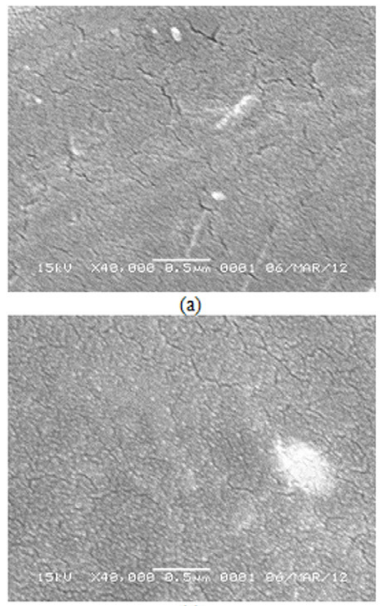



(b)

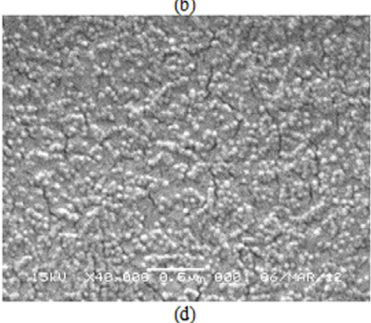

(d)

4. Mitra AK., Alur HH, Johnston TP (2007) Peptides and Proteins: Buccal Absorption, in: J. Swarbrick, Encyclopedia of Pharmaceutical Technology, Health Informa.

5. Dixit RP, Puthli SP (2009) Oral strip technology: overview and future potential. J Control Release 139: 94-107.

6. Chen MJ, Tirol G, Schmitt R, Chien C, Dualeh A et al. (2006) Film-Forming Polymers in Fast Dissolve Oral Films, The Dow Chemical Company, Bound Brook

7. Rao SV, Shao J (2008) Self-nanoemulsifying drug delivery systems (SNEDDS) for oral delivery of protein drugs: I. Formulation development. Int J Pharm 362 $2-9$

8. Sinko PJ, Singh Y (2011) Martin's Physical Pharmacy and Pharmaceutical Sciences: Physical Chemical and Biopharmaceutical Principles in the Pharmaceutical Sciences, 6th ed., Lippincott Williams Wilkins, Baltimore.

9. Hea YS, Jung YJ, Yong TK (2011) Thermal Conductivity Enhancement of Binary Nanoemulsion (O/S) for absorption application. Int J Heat Mass Tran 54: $1649-1653$

10. Yang SC, Benita S (2000) Enhanced Absorption and Drug Targeting by Positively Charged Submicron Emulsions. Drug Deliv Res 50: 476-486.

11. Fatouros DG, Bergenstahl B, Mullertz A (2007) Morphological observations on a lipid-based drug delivery system during in vitro digestion. Eur J Pharm Sci 31: $85-94$

12. Yang S, Gursoy RN, Lambert G, Benita S (2004) Enhanced oral absorption of paclitaxel in a novel self-microemulsifying drug delivery system with or without concomitant use of P-glycoprotein inhibitors. Pharm Res 21: 261-270.

13. Gaonkar AG (1991) Surface and Interfacial Activities and Emulsion Characteristics of Some Food Hydrocolloids. Food Hydrocolloid 5: 329-337.

14. Elsabee MZ, Morsi RE, Al-Sabagh AM (2009) Surface active properties of chitosan and its derivatives. Colloids Surf $B$ Biointerfaces 74: 1-16.

15. Khanna R, Agrawal SP, Ahuja A (1997) Preparation and Evaluation of Buccal Films of Clotrimazole for Oral Candida Infections. Indian J. Pharm. Sci 59:299_ 305

16. Alanazi FK, Abdel Rahman AA, Mahrous GM, Alsarra IA (2007) Formulation and Physicochemical Characterization, of Buccoadhesive Films Containing Ketorolac. J Drug Del Sci Tech 17: 183-192.

17. Rowe RC (1983) Correlation between The In Situ Performance of Tablet Film Coating Formulations based on Hydroxypropylmethyl Cellulose and Data Obtained from The Tensile Testing of Free Films, Acta Pharm. Tech 29: 205 207.

18. Peh KK, Wong CF (1999) Polymeric films as vehicle for buccal delivery: swelling, mechanical, and bioadhesive properties. J Pharm PharmSci 2: 53-61.

19. Barthel E (2007) Adhesive Contact of A Compliant Sphere to An Elastic Coated Substrate: The Thin Film Limit. J Adh 83: 729-744.

20. Callister WD (2001) Fundamentals of Materials Science and Engineering, 5th ed., John Wiley \& Sons, Inc. New York. therapeutic protein.

\section{Acknowledgement}

This work was financially supported by research grant of Bandung Institute of Technology 2013.

\section{References}

1. Fox S (2001) Business models: Contract Biopharmaceutical Manufacturing Chem. Market Rep 260: 20-26.

2. Walsh G (2010) Biopharmaceutical benchmarks 2010. Nat Biotechnol 28: $917-$ 924

3. Michael Bartholow (2011) Top 200 Drugs of 2010. Pharmacy Times. 